\title{
Advanced travel demand management policies
}

\author{
G. Galante \& M. Russo Spena \\ Dipartimento di Ingegneria Civile Edile ed Ambientale, \\ Università degli Studi di Napoli Federico II, Italy
}

\begin{abstract}
European urban and metropolitan regions are characterized by the concentration of activities in a limited area and by transit systems which coexist with individual transportation. Traditionally, travel demand management (TDM) policies have been applied to enhance the efficiency, sustainability and safety of the transportation systems, often via an increased use of transit modes. This strategy is one of the most effective to ensure: i) lower road-space occupation; ii) lower pollution; iii) lower energy consumption; iv) higher safety. Moreover, an increased transit use also has positive effects on the mobility still remaining on individual modes. Many TDM policies have been proposed in the past, based on push (say, disincentives of the car-mode) and pull (say, incentives of the transit mode) strategies, impacting at different levels on the mobility and on the activity patterns of travellers. Within the push strategies, measures can be based on regulation byquantity (limitation of use, as in restricted access areas) or by-pricing (e.g. $\mathrm{road} /$ area pricing). A more recent concept involves the use of tradable-drivingrights. The approach has already been claimed to be feasible; however, it has not reached a significant popularity among the transportation analysts nor within the decision-makers, perhaps because of difficult technical and administrative implementation, as well as some residual equity/redistribution issues. In this paper the potential of a new-generation of tradable driving rights, based on ITS (Intelligent Transportation System) is analysed. Driving rights are intended here as allowance/permits, acquired by travellers in exchange for virtuous mobility. Virtuosity is related to the contribution toward the efficiency, sustainability and safety of the mobility behaviour. Permits can be spent in exchange for nonvirtuous behaviour. The proposed approach is tested on a real network and with real data; two scenarios with different strategies in assigning permits are
\end{abstract}


assessed in order to show the ability of the model to forecast the effects of innovative travel demand policies.

Keywords: intelligent transportation systems, smart cities, travel demand management, mobility allowance and permits.

\section{Introduction}

Congestion, pollution and energy consumption are major and recurring concerns all over the world. Many solution have been proposed to deal with these challenges, ranging from network design solutions [1], possibly based on accurate knowledge of transport demand, to different solution for re-equilibrating the modal shift in transportation [2,3], where it is proved that an increased quality (also in terms of hedonic value [4]), in transit services has positive side-effects on the mobility that still remain on individual modes.

From the point of view of the economic theory the externalities created by transport can be considered as the result of the over-consumption of scarce goods (road space, environment, etc.). In these cases, the economic theory suggests the implementation of regulatory policies that can be implemented both via a bypricing and/or a by-quantity approach $[5,6]$.

To this aim, TDM (Travel Demand Management) measures have been in past years one of the possible answers to the previous concerns. They are aimed at implementing transportation systems regulations of the demand for mobility (push approach (e.g. [7]). Within the field of TDM policies pull measures are also frequently suggested. In fact, regulation could lead to a deterioration of the travellers' welfare (generally increased monetary cost for travelling - despite higher speeds - and/or switching to travel alternatives less appealing before the introduction of regulation); pull TDM measures aim at mitigating the negative effects of regulations (in practice, by restoring the generalised accessibility disrupted by regulation policies) and, as a secondary (no less important) goal, at increasing the appeal of travel choices different from the regulated ones. Moreover, both pull and push measures can impact on the spatial location of activities [8].

Non exhaustive examples of regulation-by-pricing measures are parking pricing, area, cordon and road pricing $[9,10]$ as well as and (not at an urban level) fuel taxes. Some examples of regulation-by-quantity measures are Restricted Access Areas (RAA) and parking limitation [8, 11]. Typical pull measures are public transport subsides and, at an urban level, transit systems improvement [3] and park-and-ride facilities.

\section{By-pricing and by-quantity regulation of travel demand}

From an economic theory point of view, the most natural way of applying regulation is to implement regulation by-pricing; intended to re-equilibrate the under-pricing of scarce resources such as road space and environment [12]. Regulation by-pricing has been strongly unpopular for many decades, provided that motorists were used to not being charged for their use of road and 
environmental resources; however, in recent years the implementation of pricing policies has been boosted by some public authorities, from the first pilot-test in Singapore (1975) (and the proposed but never fully implemented experiment in Hong Kong, 1983) to the well-known most recent (and successful) applications in London (since 2003) and Stockholm (in 2006). Despite successful implementations, the pricing approach has some inherent limitations. First of all, it can be theoretically shown that redistribution concerns occur [13], provided that a great part of the benefits are reserved for a minority of individuals (with high value-of-time). To mitigate such a redistribution effect local authorities are strongly required by public opinion to get the extra fund (toll revenues) for improving their public transport services. However, such a compensation is indirect, subject to political and administrative constraints. Moreover, it is not an easy task to properly redistribute benefits among the population. A second major drawback is that given goals in terms of congestion (or pollution) can be only indirectly reached by carefully adjusting the pricing level. The adjustment is strongly sensitive on many parameters: the performances of the non-priced travel alternatives, the distribution of the value-of-time among the individuals, the current congestion level, the elasticity of travel demand, etc.

Regulation by-quantity differs from pricing. Redistribution among individuals is not a concern, provided that (at least in theory) travellers' value-of-time does not affect these measures. Moreover, the desired effect in terms of trafficexternalities reduction can be directly achieved. For instance, the number of cars allowed to enter a given area can be directly controlled or quite directly controlled by limiting the number of available parking spaces in the area. However, some mobility issues are not easily compressible (rigid demand) and it can happen that the regulation goal is beyond the demand elasticity. In the case of regulation-bypricing, this can be self-adjusted (costly, from a welfare point of view) via the sacrifice of some other individual needs in order to accommodate the increased monetary cost of travelling, but such a mechanism is not suitable in the case of regulation-by-quantity, so that public authorities have to limit themselves to suboptimal goals in order to not disrupt the accessibility beyond some acceptable extent. In that way, restricted access areas and/or parking limitation can be applied only to limited areas. Finally, it is more difficult to continuously adjust regulationby-quantity measures with respect to dynamically evolving context, provided that it is not possible to rely on self-adjusting mechanisms.

In order to combine the advantages of the regulation by-pricing and byquantity, a third way has been explored in the last few years, even if (indented as a TDM measure for urban areas) with less popularity with respect to more traditional policies. This is the tradable-driving-rights (TDR) approach which seems, at least from a theoretical point of view, a promising alternative $[14,15]$.

It belongs to the family of Tradable Permits. In turn, this category of instruments is part of the broader family of transferable permits (TP) [16]; defined in a general way (not necessarily applied to transportation) as instruments that set quantified physical constraints in the form of obligations, permits, credits or rights allocated to target groups of agents consuming scarce resources; and the permission granted to the agents to transfer these quotas [17]. In the field of 
transportation, the allocation of quotas within urban areas has been proposed for instance by [18] and [19]. A credit-based pricing mechanism has also been proposed by [20,21] and [22]. The basic approach in all cases (with relevant variants) is that travellers (typically motorists) receive a given allocation of credits (quotas - in principle monetary), which can be used to travel for free on a road network or within a zone. Once the quota is consumed, the motorists have to purchase other credits or are subject to charging for journeys [23]. The impact of TDR, the final balance and the total cost from a welfare point of view do not depend on the initial allocation of rights only in theoretical cases [24].

The instrument is particularly appropriate in situations of uncertainty with regard to response of travellers and allows for separating efficiency from equity, thanks to the initial allocation of quotas. Moreover, from a political point of view, allocation of quotas free of charge may be seen as a means of avoiding additional taxes, and this enhances the acceptability of the tools where pricing policies are unpopular.

\section{Using ITS}

Some limitation and difficulties apply to the practical implementation of tradable driving rights. One surely is the cost of administration over a large number of travellers. Even if this difficulty is similar in the case of electronic road pricing (and is now better enabled by innovative technologies), in the case of tradable driving rights it is exacerbated where the implementation is based on the regulation of the travelled vehicle-per-kilometre. In this case, continuous (or semi-continuous - or continuously estimable) tracking of vehicles is required and the system only partially can be based on the same technologies (typically road-side) used for electronic toll collection [25].

It is possible to answer many of the previous concerns by means of an innovative and integrated application of the ITS (Intelligent Transportation Systems) approach.

The term ITS (Intelligent Transportation Systems) refers to the application of ICTs (Information and Communication Technologies) to transportation systems. Examples of ITS applications range from driving assistance [26, 27] to traffic regulation [1], from electronic toll collection to travellers' information [28]. A comprehensive list of all kinds of ITS applications is far beyond our scope.

The most diffused ITS applications for TDM relate to the enforcement of Restricted Access Areas (RAA) and to electronic tooling for congestion-pricing. Of course, RAA and road-pricing are TDM measures that have been proposed and (partially) applied also before the massive introduction of ICT in transportation; however, the ITS-revision of these policies has drastically boosted the suitability of these kinds of measures; for instance, the London cordon-pricing implementation is probably unimaginable without a massive injection of ICT. 


\section{The proposed approach}

ITS can boost the application of TDR. This can be implemented within a smartcity approach. As stated in [29]: "in Smart Cities digital technologies translate into better public services for citizens, better use of resources and less impact on the environment". Figure 1 below shows the overall approach of an ITS-assisted strategy centred on the pivotal concept of smart cities and based on a TDR solution.

\begin{tabular}{|c|c|c|}
\hline \multicolumn{3}{|c|}{$\begin{array}{l}\text { General Objective: smart policies and smart citizens in smart cities } \\
\text { Enabling and implementation of Advanced Travel Demand Management options } \\
\text { toward sustainability, effectiveness, acceptability and equity of mobility contexts }\end{array}$} \\
\hline $\begin{array}{l}\text { Technological } \\
\text { Innovation } \\
\text { 1. Integration of } \\
\text { existing technologies } \\
\text { 2. From a mode-centric } \\
\text { to a traveller-centric } \\
\text { technology }\end{array}$ & $\begin{array}{l}\text { Policy-making } \\
\text { Innovation }\end{array}$ & $\begin{array}{l}\text { Citizens' attitudes } \\
\text { Innovation } \\
\text { 5. Citizens as active } \\
\text { actors of the } \\
\text { transportation policy } \\
\text { 6. Awareness of travel- } \\
\text { behaviour impacts }\end{array}$ \\
\hline
\end{tabular}

Figure 1: The overall concept of the proposed strategy.

In our application, TDR are intended as allowance/permits acquired by travellers in exchange for virtuous mobility behaviour, where virtuosity is related to the contribution toward the efficiency, sustainability and safety of the transportation system. Thus, permits are not necessarily based on monetary purchasing; in this sense the aim is to overrun the current TDR proposals. The concept assumes that each citizen (possibly each household) owns a (properly designed) monthly (or weekly or annual) mobility allowance that is automatically cleared and renewed each month (or week or year). Each time he/she travels in a virtuous way (e.g. by entering critical areas of the city using public transport or non-motorised modes) his/her allowance is increased while each time he/she travels in a vicious way his/her allowance is decreased.

The amount of the initial mobility allowance, the amount of allowance subtracted or added for each possible vicious or virtuous travel behaviour and the actual computation of the viciousness or virtuosity of each possible travel behaviour play the role of design variables for the implementation of the solution. The nature of the solution, as discussed above, is also shown by figure 2; some conceptual simplifications are introduced for sake of simple illustration, the travel demand is considered to be rigid at a multimodal level and only the mode-choice level of choice (that is, the one mostly directly affected by the proposed strategy) is considered. 


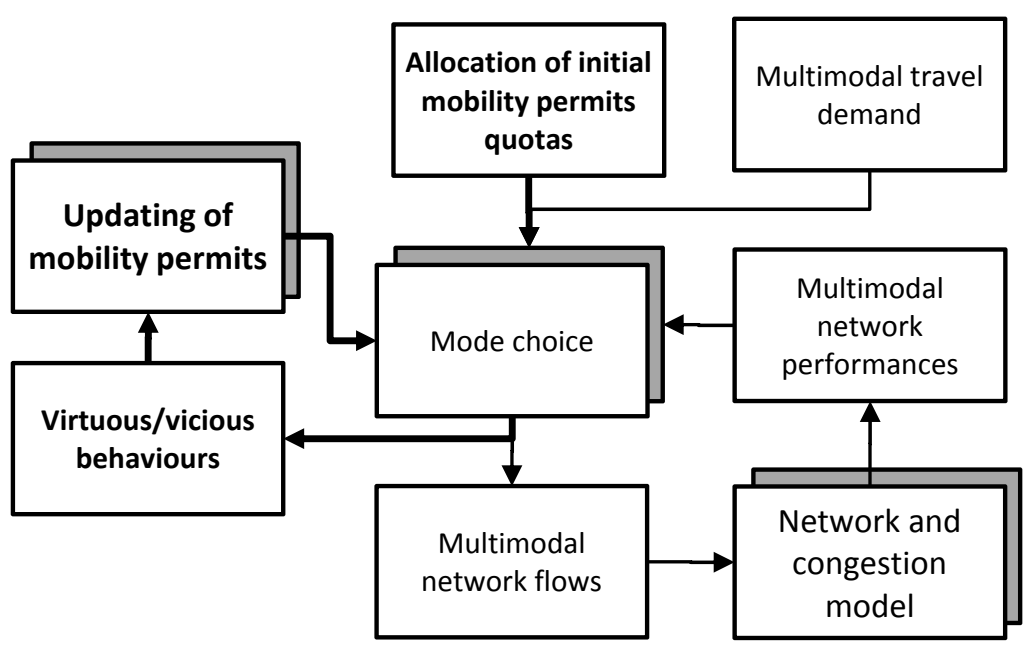

Figure 2: Application scheme for the proposed approach.

\section{An application}

The implementation of the policy to the city of Napoli (South-Italy) will reveal some more of the nature of the application. The example shows how the proposed policy can be applied in order to forecast the effects of an advanced travel-demand management scheme. A system of demand models, previously developed in [30] has been adapted; it allows for an enhanced representation of the mobility patterns. In particular, it is possible to simulate the participation to activities at a household level and thus the attribution of mobility permits to households. It is also possible to consider that given activities (at given destinations) have to be carried out and that the use of different modes of transport could have, as a consequence, a different scheduling of activities, and/or different travel frequencies and/or activity substitution or different arrangements within the members of the household. The actual implementation of the employed model has been subject to a calibration, based on data collected at the University of Naples during previous research. Subjects were asked to take a one-week diary of activities and of associated travels. Some of the demand levels haven't been calibrated and the information gathered from the survey has been taken as fixed. This is the case for both the household weekly activity list and the weekly activity list of each individual (so the model of participation to activities is solved in an inelastic way). The level related to the individual daily activity list and to the (tour-based) travel model have been calibrated. The way the adopted model mainly influences the experiment is in terms of modal choice and destination choices of trip chains. The model is far too complex to be summarized here and the reader is encouraged to read [30]. In the do-nothing scenario, the mode share related to car is around $67 \%$. 
Given that it is hypothesized to assign the mobility-allowance on a monthly basis, the daily activity list is not directly relevant and most of the information required to identify the potential effects of this TDM measure (and not the actual ones) is the mode-choice model. In order to simulate the potential effects of a TDM strategy, the city of Naples has been divided into eleven traffic zones. The average size of each traffic zone is in the magnitude of 90,000 inhabitants. Based on the transportation supply of the public transport mode and on the attractiveness of the zones (measured by the number of working places, retail and urban services in the zones) the passive accessibilities of the eleven zones to be reached by transit have been computed. Of these, the four most accessible (by transit) have been considered; these are the zones in light grey in Figure 3 below. The average modeshare for cars toward these zones is around 55\% in the do-nothing scenario.

The scenario with the application of the proposed approach based on mobility allowances has been built by considering the observed travel demand. Given the demand estimated from the survey at an household level and for a week (assumed to be identically repeated over a month), a proper assignment of mobilityallowances has been done in such a way that not all observed car-trips toward the most transit-accessible zones can be still accommodated. In particular, these zones have been charged by mobility allowance that are not able to cover $10 \%$ of the car demand observed in the do-nothing scenario. In other terms, a cut-off of $10 \%$ of the car mode share has been fixed as a goal of the policy and this has been pursuit by simply cutting-off the corresponding amount of mobility allowances.

The effect of this policy, as shown in Figure 3 (scenario 1), is as expected, given that almost $10 \%$ of the mobility by car (from $8 \%$ to $10 \%$, depending on the considered zone) is shifted from the car-mode to the transit mode. The effect is not perfectly correspondent to the amount of mobility allowance that has been cut, because some of the travellers re-adapt their choices. In particular, they shift to transit in the case of travels directed to other zones in order to save mobility allowances to be spent in the controlled zones. This phenomenon is very limited as we have properly chosen the zones where the policy is implemented. However, this shows the elasticity and self-adjustment ability of the policy.

A different (unfair) demand management strategy is adopted for comparison: the same amount of mobility allowances is subtracted, but this has been done by considering the subtraction has an effect on trips directed to the less-transitaccessible zones (dark grey in Figure 3 below). The effect is depicted in figure 3 and refers to the percentage of trips shifted to transit in the same zone considered for scenario 1. Not surprisingly, a shift to transit for trips directed in the most transit-accessible zone once again can be observed, even though in this case they are not directly interested by the control policy. This result is due to the fact that the travellers react by reducing the number of car trips toward the most transitaccessible zones in order to save mobility allowances to be spent in the less transitaccessible zones. It is worth noting that in this case the observed shift is less than in scenario 1 because not all households are able to compensate between trips directed to different zones; indeed, not all destinations could be available in the weekly activity list of the household. However, the applied policy shows a potential that cannot be exploited in the case of simple by-limits approaches. It is 


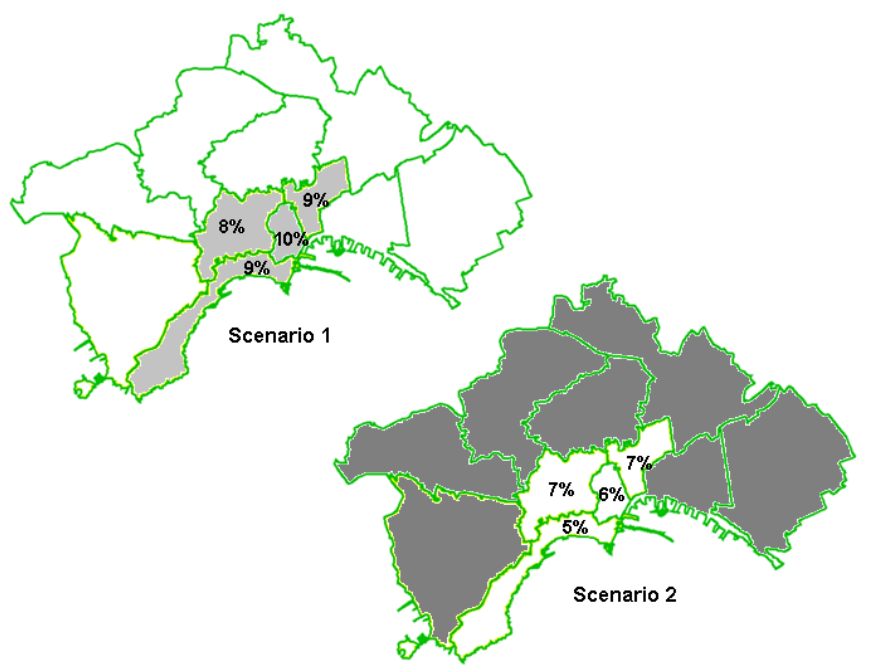

Figure 3: Decrement of car use after the same amount of mobility allowances are paid in the case of car trips toward the most transit-accessible zones (scenario 1) or toward the other zones (scenario 2).

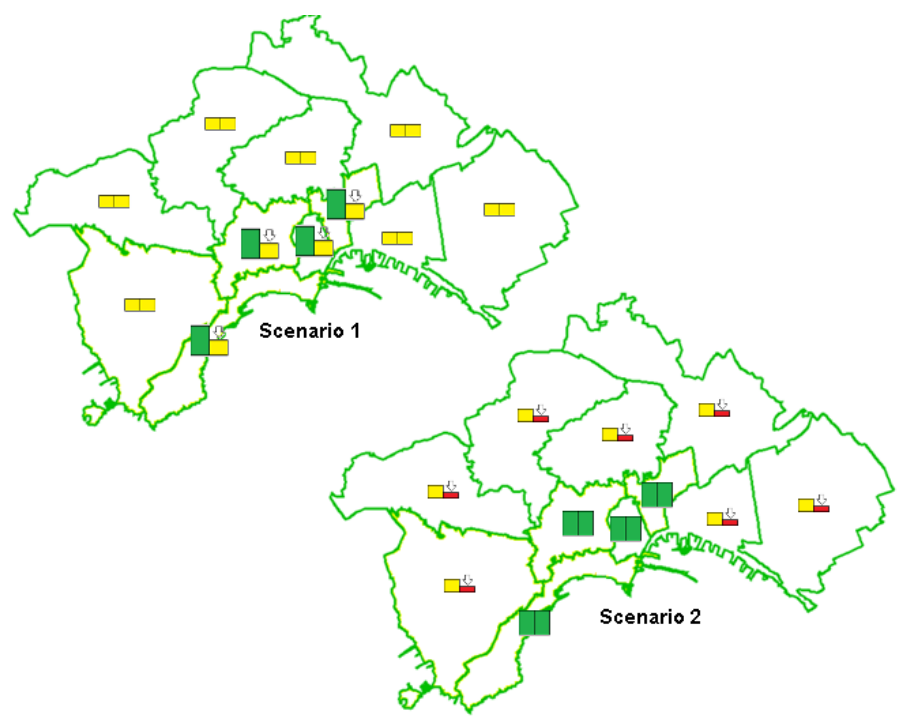

Figure 4: Tendency of accessibility after the same amount of mobility allowances are paid in the case of car trips toward the most transitaccessible zones (scenario 1) or toward the other zones (scenario 2).

worth noting that, in order to capture this effect, a complex travel demand model is needed, able to deal with weekly activity lists at a household level. Moreover, a mobility allowance policy has to be applied at a household level. Figure 4 also shows how the way in which the mobility allowance strategy is designed plays a 
role. Not only the strategy adopted in scenario 2 is less efficient but it is also strongly unfair with respect to the results in terms of total accessibility distribution across zones. The magnitude of the forecasted effects is about $10 \%$. For comparison, consider that the observed effect of other very successful TDM policies is not really different in terms of magnitude, for instance: $18 \%$ for the London congestion charge [31] and 20\% for the Stockholm strategy [32].

\section{References}

[1] Bifulco G.N., Cantarella G.E., Simonelli F. Design of Signal Setting and Advanced Traveler Information Systems. Journal of Intelligent Transportation Systems, 18(1), 30-40, 2014

[2] Cascetta E., Cartenì A. A quality-based approach to public transportation planning: theory and a case study. International Journal of Sustainable Transport, 8(1), 84-106, 2014

[3] D’Acierno L., Gallo M., Biggiero, L., Montella B. Replanning public transport services in the case of budget reduction. WIT transaction on the Built Environment, 138, 77-88, 2014

[4] Cascetta E., Cartenì A. The hedonic value of railways terminals. A quantitative analysis of the impact of stations quality on travelers behavior. Transportation Research Part A, 61, 41-52, 2014

[5] Liu W., Yang H., Yin Y. Traffic rationing and pricing in a linear monocentric city, Journal of Advanced Transp., published on-line, doi 10.1002/atr.1219, 2012

[6] Hepburn C. Regulation by prices, quantities, or both: a review of instrument choice. Oxford Review of Economic Policy, 22(2), 226-247, 2006

[7] Han D., Yang H., Wang X.L. Efficiency of the plate-number-based traffic rationing in general networks. Transp. Res. Part E, 46(6), 1095-1110, 2010

[8] Biggiero L., The impact of transport management on local activities system: The role of limited traffic zones. WIT Transaction on the Built Environment, 138, 669-678, 2014

[9] Rouwendal J., Vorhoef E.T. Basic economic principle of road pricing: From theory to application. Transport Policy, 13(2), 106-114, 2006

[10] Basbas S., Politis I., Urban road pricing and sustainable transportation systems: The Thessaloniki central area case, International Journal of Sustainable Development and Planning, 3(1), 1-15, 2008

[11] Gallo M., D’Acierno, L., Montella B. A multilayer model to simulate cruising for parking in urban areas. Transport Policy, 18(5), 735-744, 2011

[12] Pigou A. C., The economics of welfare, Macmillan, London, 1920

[13] Hau T.D. Economic fundamentals of road pricing: a diagrammatic analysis. The World Bank, Policy Research Working Paper Series 1070, 1992

[14] Crals E., Vereeck L., Road pricing versus tradable entry rights: a transaction cost approach, WIT Transactions on the Built Environment, 89, 881-890, 2006 
[15] Goddard H. Using tradable permits to achieve sustainability in the world's large cities: policy design issue and efficiency conditions for controlling vehicle emissions, congestion and urban decentralization with an application to Mexico City. Environmental and resource economies, 10(1), 63-99, 1997

[16] Nie Y. Transaction cost and tradable mobility credits. Trans. Res. Part B, 46(1), 189-203, 2012

[17] OECD, Domestic transferable permits for environmental management, design and implementation. Organisation of Economic Cooperation and Development, Paris, 2001

[18] Verhoef E, Nijkamp P, Rietvald P, Tradable permits: their potential in the regulation of road transport externalities. Environment and Planning B: Planning and design, 24, pp. 527-548, 1997

[19] Marlot G., Réguler la congestion par de permis négociables: une solution au dilemma efficacité/acceptabilité. Proceedings of the $8^{\text {th }}$ World Conference on Transportation Research, Antwerp, 1998

[20] Kockelman K.M. \& Kalmanje S., Credit-based congestion pricing: a proposed policy and the public's response. Transportation Research Part $A$ 39, pp. 671-690, 2005

[21] Yang H., Wang X. Managing network mobility with tradable credits. Trans. Res. Part B, 46(3), 580-594, 2011

[22] Nie Y, Yin Y. Managing rush hour travel choices with tradable credit scheme. Trans. Res. Part B, 50, 1-19, 2013

[23] Daganzo C.F., A Pareto Optimum congestion reduction scheme. Transportation Research Part B, 29, pp. 139-154, 1995

[24] Stavins R., Transaction costs and tradable permits. Journal of Environmental Economics and Management, 29, pp. 133-148, 1995

[25] de Palma A., Lindsey R. Traffic congestion pricing methodologies and technologies. Trans. Res. Part C, 19(6), 1377-1399, 2011

[26] Bifulco G.N., Pariota L., Brackstone M., McDonald M., Driving behaviour models enabling the simulation of Advanced Driving Assistance Systems: Revisiting the Action Point paradigm. Transportation Research Part C, 36, 352-366, 2013

[27] Bifulco G.N., Pariota L., Simonelli F., Di Pace R. Development and testing of fully adaptive cruise control systems. Transportation Research C, 29, 156-170, 2013

[28] Ben-Elia E., Di Pace R., Bifulco G.N., Shiftan Y. The impact of travel information's accuracy on route-choice. Transportation Research Part C, 26, 146-159, 2013

[29] http://ec.europa.eu/digital-agenda/living-online/smart-cities

[30] Bifulco G. N., Cartenì A., Papola A. An activity-based approach for complex travel behaviour modelling. Eur. Transp. Rev., 2(4), 209-221, 2010

[31] Santos G., Fraser G. Road pricing: lessons from London, Economic Policy, 21(46), 469-479, 2006

[32] Eliasson J. Lesson from the Stockholm congestion charging trial. Transport Policy, 15(6), 395-404, 2008 